\title{
Fault detection of fabrics using image processing methods
}

\section{Görüntü işleme yöntemleri kullanarak kumaş dokularında hata tespiti}

\author{
Kazım YILDIZ ${ }^{1 *}$ Önder DEMIR ${ }^{1}$, Eyüp Emre ÜLKÜ'1
}

1Department of Computer Engineering, Technology Faculty, Marmara University, Istanbul, Turkey. kazim.yildiz@marmara.edu.tr, odemir@ marmara.edu.tr, emre.ulku@ marmara.edu.tr

\section{Abstract}

This paper presents a computer aided detection (CAD) system which uses wiener filter based approach for detection of defects in poplin fabric. The defective fabric images are taken with the help of the digital camera. The developed system consists of three phases, including preprocessing, segmentation and detection of fabric defect. In preprocessing phase, a RGB to gray level conversion and image enhancement operations were applied to digital camera images. In segmentation phase, background of the gray level image segmented using morphologic operations. Then, segmented image was converted to binary image to facilitate fabric defect detection process. Fabric defect detection was performed using wiener filter in the detection phase of the system. Wiener filter is applied to binary level image to eliminate structures which are not defect. The developed detection system applied on defective poplin images for detection. The obtained results on different kinds of fabric defects show that the proposed algorithm gives promising results.

Keywords: Texture surface, Defect detection, Wiener filter, Computer aided detection, Segmentation

\section{Introduction}

Surface detection in the quality control phase of the wood, paper, fiber and leather industries is a very important issue. For this purpose, image analysis and processing techniques are widely used in automatic defect detection and classification of surface defects. Especially in the textile industry, defect detection is a challenging process when all quality control processes are taken into account.

In many textile companies, the fabric quality control process is carried out manually by the employees. . For this reason, the detection process is a human eye-related process that can vary from person to person without being objectively evaluated. The quality control process is very difficult issue because of using different types of fabrics and trying to detect different types of defects. In this paper, a Wiener filter-based defect detection algorithm is proposed for detecting well-known fabric defects. In the study, it is aimed to find some common defects such as hole, tear, warp, weft fault, knot and foreign yarn.

Due to defects on the fabric surface, a $45-65 \%$ loss in fabric quality can be observed [1],[2]. Because of these significant losses, the process of detecting defects in the textile industry must be highly effective and objective By reason of the difficult and slow operation of conventional defect detection systems, detection can be performed automatically by developing new algorithms and systems. The variety of defect types and defective zones make it difficult to design an alternative detection system. In addition to this, some of the textile defects
Öz Bu çalıșmada poplin kumașta hata tespiti için wiener filtre tabanlı bilgisayar destekli tespit sistemi sunulmaktadır. Hatall kumaş görüntüleri dijital kamera yardımıyla alınmıștır. Geliștirilen sistem önișleme, bölütleme ve kumaș hata tespiti olarak 3 asamadan olușmaktadır. On isleme așaması, dijital görüntülere RGB seviyeden gri seviyeye çevirme ve görüntü iyileștirme adımlarından olușmaktadır Bölütleme aşamasında, gri seviye görüntünün arka planı morfolojik ișlemler ile bölütlenmistir. Ardından, bölütlenen görüntü, hata tespit işlemini gerçekleștirmek için ikili seviye görüntüye çevrilmiştir. Kumaş hata tespiti, hata tespit sistemi sirasinda wiener filtre kullanılarak gerçeklenmiștir. Wiener filtre ikili seviyedeki görüntüye hatalı olmayan alanların elimine edilmesi amacıyla uygulanmıștır. Gerçeklenen sistem, tespit ișlemi için hatalı poplin kumașlara uygulanmıștır. Elde edilen sonuçlar, geliştirilen algoritmanın farklı tip kumaş hatalarında iyi sonuçlar vermektedir.

Anahtar kelimeler: Doku yüzeyi, Hata tespiti, Wiener filtre, Bilgisayar destekli tespit, Bölütleme

are very similar to each other. This is considered another difficulty in the detection phase.

Due to the detection of defects is an important task in the textile industry, various applications and algorithms have been developed to accomplish this task [3]-[9]. In a previous study, [10] the authors have been discussed the applications which are made in this area in detailed. They consider on different kinds of works which are done in this process. Chan and Pong [3] have proposed a Fourier-based algorithm for detection of fabric defects. Four kind of defects have been detected with the proposed algorithm. From central spatial frequency spectrum seven characteristic parameters have been extracted for classification process. Amet and friends have used wavelet and gray level co-occurrence matrix for detection of defects. They have used Mahalonobis distance for classify each wavelet sub window as defective and non-defective [11]. In another study [12], local homogeneity and neural network based defect detection algorithms have been presented. After the detection process energy features have been obtained from images and then classified. Guzaitis and Verikas have served an approach which is based on fusion analysis for surface detection. They have combined the global and local features together for detection process. Their results have showed that the proposed work can be applied on defect detection process of surfaces which have statistical features. The algorithm has insensitive to the lighting changes [13]. Li and friends have defined the software and hardware based combining approach to define defects in real time. For the software part, they have designed Otsu and Golden Image Subtraction method for detection. Their results on different kinds of defects have showed promising 
results [14]. Tsang and friends have prepared a novel algorithm for detection process. They have called it as an Elo Rating method on inspection process. The inspection has been achieved by fair matches between partitions from images. Their detection rate for 336 patterned images has been found about $97 \%$. Their work has so effective on different kinds of defects [15]. Hu has proposed a novel method which is based on genetic elliptical gabor filter. The gabor parameters have been tuned by the genetic algorithm. The performance evolution of the word has been presented for variety of samples which are different types, shapes and sizes and background. The designed approach gives promising results on texture surfaces [16].

In this paper a wiener filter based defect detection process in binary level was designed. The surfaces were obtained from poplin fabric. These images were converted to gray level in preprocessing step and then the enhancement process was applied. For segmentation and detection processes, the newly designed filter based algorithm was applied on these surfaces for the inspection process.

The organization of this paper is as follows: In section 2, the developed CAD system and its' different phases are described In section 3, the results obtained on different defects with the designed system are given Finally, in the conclusion section, the observations obtained from the study and the researches to be carried out in the future are evaluated.

\section{Developed CAD system}

The block diagram of the CAD system was presented in Figure 1. The images are taken with Canon 600D which has a macro snap feature. During the preprocessing phase, RGB images were converted to gray level image and then the quality of the obtained gray level images were enhanced. During the segmentation phase, background of the image was eliminated. Then, the segmented image was converted to binary image. In the next phase, image was filtered and fabric defects were detected.

\section{$2.1 \quad$ Preprocessing phase}

The preprocessing phase of an image processing application serves to enhance the image quality in order to increase the success of the system. The aim of the preprocessing phase is making images suitable for segmentation. The preprocessing phase consists of two main parts. These parts are gray level conversion and enhancement of the image for segmentation phase.

Digital camera images of the poplin fabric are true color RGB images. RGB images are converted to gray level intensity images. This conversion is performed by eliminating the hue and saturation information while retaining the luminance. Gray level intensity (GLI) value was calculated according to R, G, B values by the formula in equation 1 where $\mathrm{W}$ are weight factors [17].

$$
\mathrm{GLI}=W_{R} * \mathrm{R}+\mathrm{W}_{G} * \mathrm{G}+W_{B} * \mathrm{~B}
$$

Then, contrast of the gray level image is increased to enhance the image for segmentation. The contrast enhancement process is performed by mapping the values of the input intensity image to new values such that $1 \%$ of the data is saturated at low and high intensities of the input data.

\subsection{Segmentation phase}

The term image segmentation refers to the partition of an image into a set of regions. The aim of the segmentation is for the regions to represent meaningful areas of the image. The regions might be sets of border pixels that are grouped into such structures as line segments or circular segments. Regions may also be defined as groups of pixels having both a border and a particular shape such as a circle or a polygon [18].

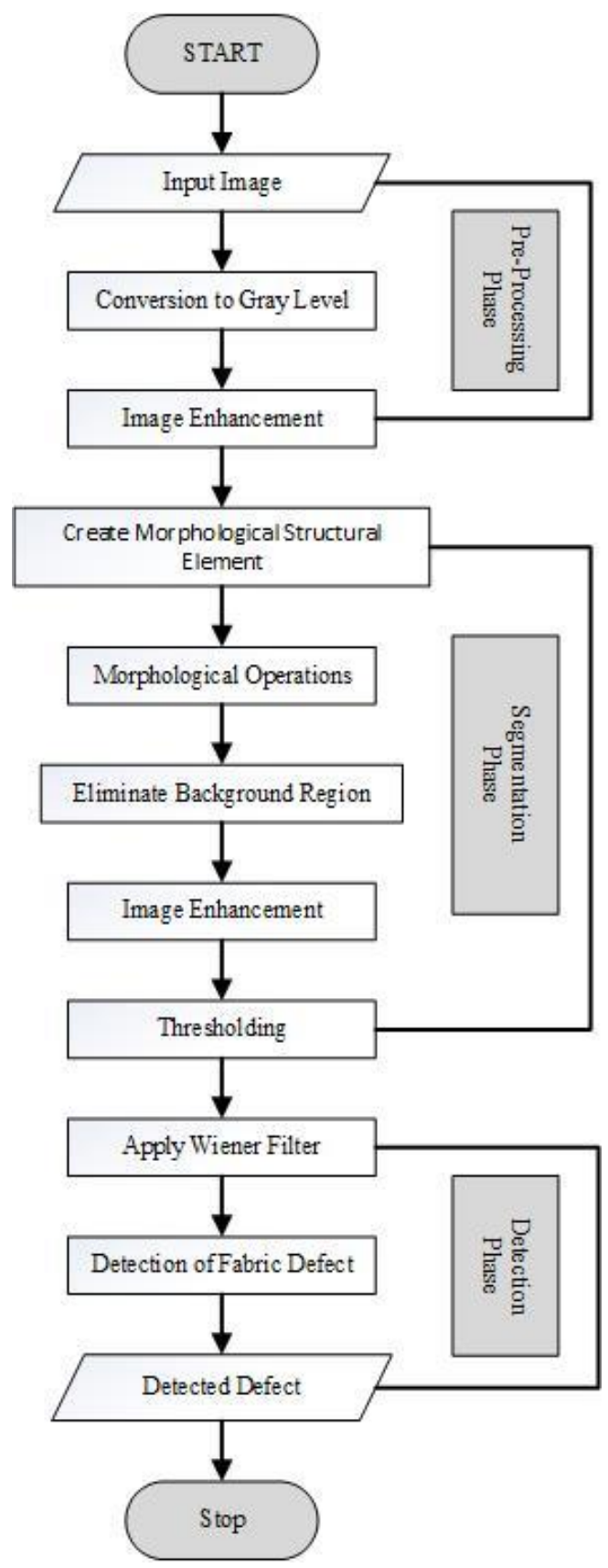

Figure 1: Block diagram of the developed system.

For the detection of fabric defects, the foreground regions on the image are the actual intended areas. The segmentation phase of the developed system is designed to ignore and eliminate the background regions. Morphologic operations are performed to eliminate the background of the gray level poplin images. A structure element is created to erode background texture of the image. 
Erosion is one of the fundamental operations in morphological image processing. Erosion makes objects thinner in digital image processing [19],[20]. Mathematical operation of erosion is described in equation 2 where $\mathrm{X}$ is image, $\mathrm{B}$ is structure element, $\mathrm{p}$ is coordinate pair of $\mathrm{X}$ and $\mathrm{b}$ is coordinate pair of $\mathrm{B}$. Original objects in a binary image are shown in Figure 2(a) and eroded objects are shown in Figure 2(b).

$$
X \Theta B=\left\{p \in Z^{2}: p+b \in X, \forall b \in B\right\}
$$

Due to the direction and pattern size of the poplin texture, a vertical line structure was created. The length of the line structure is two pixels. After completion of the segmentation, the enhancement process is performed again on segmented image. After the enhancement process, images are converted into binary images with threshold. The output image replaces all pixel values in the original image by replacing with value 1 (white) or value 0 (black) according to a luminance threshold value. If luminance of the original pixels are greater than the threshold value, all pixels replaces with value 1 (white) and all other pixels replaces with the value 0 (black) [21]. The applied threshold value by the system is 0.5 .

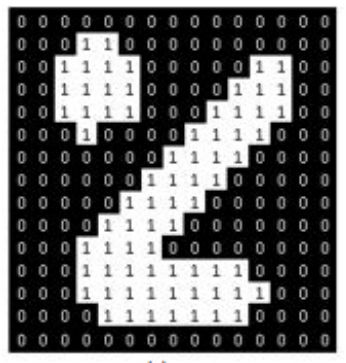

(a)

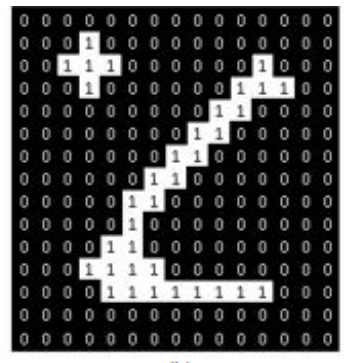

(b)
Figure 2: Original and eroded objects.

Each pixel with a value of 1, which is located in the image matrix during the adjacency examination, is subjected to an examination of adjacency in 8 directions. An adjacent pixel with a value of 1 identified in any direction is labeled with the same label number, and is subjected to an adjacency examination in 8 directions. According to decision rule, small sizes can be ignored and unlabeled [22]. In Figure 3(a), the binary image adjacencies are shown, in Figure 3(b) the labeled and unlabeled adjacencies are shown. If a size of an object is smaller than 4 pixels, the object is unlabeled. Label matrix is shown in Figure 3(c).

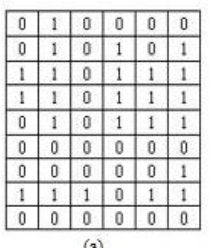

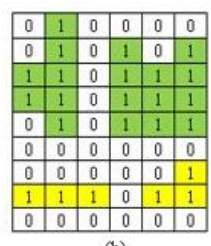

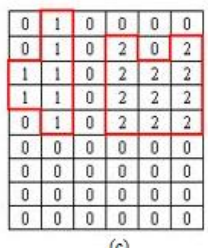

Figure 3: The adjacency examination and labeling process [22]

\subsection{Detection phase}

In the detection phase, a Wiener filter is applied on the binary image to facilitate the detection of fabric defects. Wiener filter eliminates the structures which are not fabric defect. Wiener filter is a two dimensional adaptive noise removal filter. Wiener filter is based on statistics estimated from a local neighborhood of each pixel.
Adaptive Wiener filter is applied on the binary image using neighborhoods of size 2-by-2 to estimate the local image mean and standard deviation. A pixelwise Wiener filter for image is described on equation 3 where $v^{2}$ is the noise variance [23]. Wiener filter estimates $\mu$ as local mean and $\sigma$ as variance where $v^{2}$ is the noise variance.

$$
b\left(n_{1}, n_{2}\right)=\mu+\frac{\sigma^{2}-v^{2}}{\sigma^{2}}\left(a\left(n_{1}, n_{2}\right)-\mu\right)
$$

As mentioned before, according to the decision rule, small sizes can be ignored and unlabeled [22],[23]. After Wiener filter implementation, largest area on the binary image is detected. The pseudo code of the detection phase for largest area is given. Actually this part belongs to detection part with wiener filter. This largest area shows the fabric defect. Pseudo code of the detection rule as;

1. Apply Wiener Filter on the image,

2. Calculate areas of ROI,

3. Find the ROI which has largest area(ROImax),

4. Mark ROImac on image,

5. Remove other ROIs.

\section{Results}

In this study, fabric defect types such as hole, knot, tear, and foreign yarn were detected easily by the designed system. Warp (vertical) and weft (horizontal) type defects were also detected. The proposed algorithm was effective on non-directional faults. Directionality means these kinds of defects can be vertical or horizontal way. Actually the designed system was not so effective on these kinds of defects but there should be different algorithms for detection of these kinds of faults. The original image, preprocessed image and non-defected image were all shown in Figure 4. Figure 5 shows the results of the proposed algorithm on defected images. Original images of different kinds of defects such as hole, knot, tear, foreign, warp, weft are shown in the column a. In the column b, the enhanced images of original images are shown. Enhanced images facilitate the detection of defects. In these images defects are seen more specifically. And in the last column detected defects can be seen. These defects were detected with the help of morphological operations and Wiener filter.

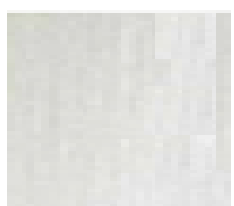

a

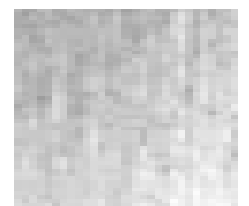

b

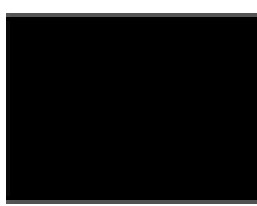

C
Figure 4: (a): The non-defected original image,

(b): Preprocessed image, (c): The result of non- defected image.

\section{Conclusion}

In this paper, a CAD system which uses Wiener filter for detection of defects in poplin fabrics was prepared. At first, defective images were taken from the poplin fabric surface then in the preprocessing phase, the original images were converted to gray level. The quality of these new images were enhanced successfully for segmentation. In segmentation part of the CAD system, structural element was used to detect the neighborhood elements effectively. So, the defective regions on the images can be seen on gray level distinctly. Based on the 
given threshold value, the defective image was converted to binary level and defective zone was detected. The defect detection process with the proposed system helps to perform the fabric quality control process in a more objective, time and cost effective way compared to the conventional system. Further studies will be on different kinds of fabrics and defects. Also more effective algorithms will be designed in order to detect the more complicated faults.

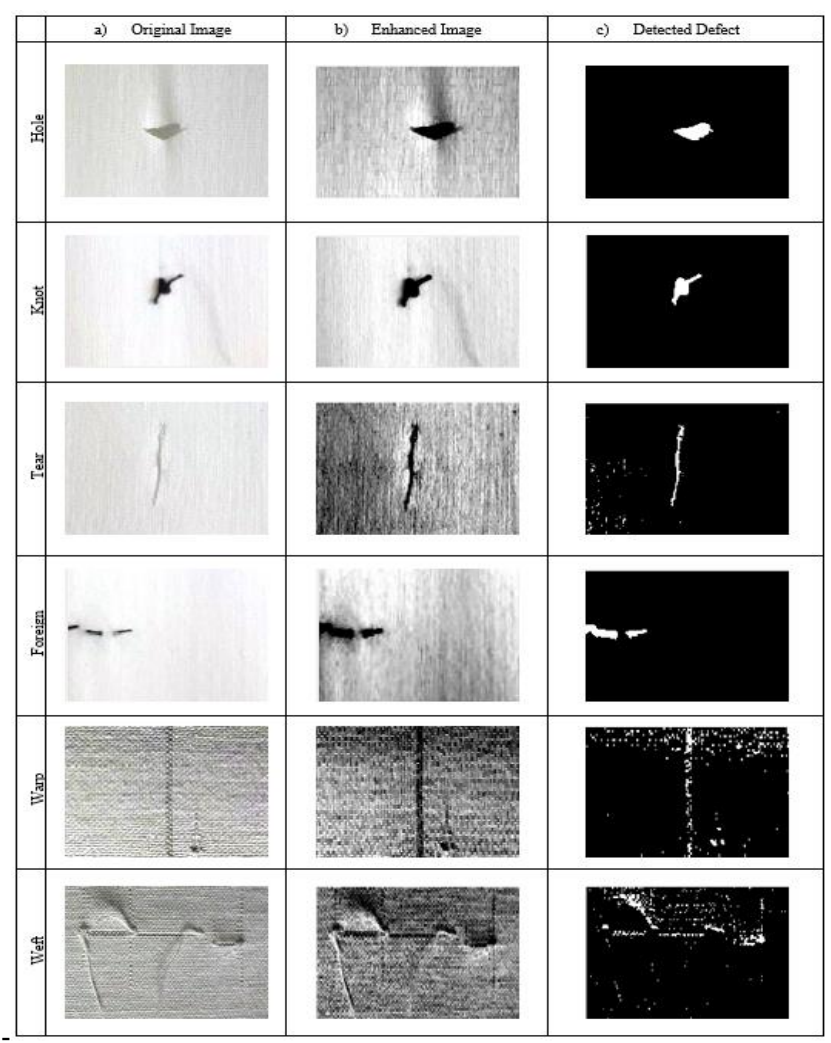

Figure 5: The obtained images of different kinds of defects with the proposed approach.

\section{References}

[1] Cho CS, Chung BM, Park MJ. "Development of real-time vision-based fabric inspection system". IEEE Transactions on Industrial Electronics. 52(4), 1073-1079, 2005.

[2] Kumar A. "Computer-vision-based fabric defect detection: a survey". IEEE Transactions on Industrial Electronics. 55(1), 348-363, 2008.

[3] Chan CH, Pang GK. "Fabric defect detection by Fourier analysis". IEEE transactions on Industry Applications. 36(5), 1267-1276, 2000.

[4] Han Y, Shi P. "An adaptive level-selecting wavelet transform for texture defect detection". Image and Vision Computing, 25(8), 1239-1248, 2007.

[5] Tsai DM, Hsiao B. "Automatic surface inspection using wavelet reconstruction". Pattern Recognition. 34(6), 1285-1305, 2001.
[6] Yang X, Pang G, Yung N. "Robust fabric defect detection and classification using multiple adaptive wavelets". IEE Proceedings-Vision, Image and Signal Processing. 152(6), 715-723,2005.

[7] Zhi YX, Pang GK, Yung NHC. "Fabric defect detection using adaptive wavelet". International Conference on Acoustics, Speech and Signal Processing, Salt Lake City, UT, USA , 7-11 May 2001.

[8] Hanbay K, Talu MF, Özgüven ÖF. "Fabric defect detection systems and methods-a systematic literature review". Optik-International Journal for Light and Electron Optics. 127(24), 11960-11973,2016.

[9] Jie L, Quan H, Mingde B, Fei A. "Fabric Defect Detection Using Adaptively Tuned Gabor Filters". International Journal of Signal Processing, Image Processing and Pattern Recognition. 9(8), 39-58, 2016.

[10] Ngan HY, Pang GK, Yung NH. "Automated fabric defect detection-a review". Image and Vision Computing, 29(7), 442-458, 2011.

[11] Latif Amet A, Ertüzün A, Erçil A. "An efficient method for texture defect detection: Sub-band domain co-occurrence matrices". Image and Vision computing, 18(6), 543-553, 2000.

[12] Rebhi A, Benmhammed I, Abid S, Fnaiech F. "Fabric defect detection using local homogeneity analysis and neural network". Journal of Photonics, 2015, 1-9, 2015.

[13] Guzaitis J, Verikas A. "Image analysis and information fusion based defect detection in particleboards". Elektronika ir Elektrotechnika, 71(7), 67-72, 2015.

[14] Li P, Zhao Z, Zhang L, Zhang H, Jing J. "The real-time vision system for fabric defect detection with combined approach". 8th International Conference on Image and Graphics, Tianjin, China, 13-16 August 2015.

[15] Tsang CS, Ngan HY, Pang GK. "Fabric inspection based on the Elo rating method". Pattern Recognition. 51, 378-394, 2016.

[16] Hu GH. "Automated defect detection in textured surfaces using optimal elliptical gabor filters". Optik-International Journal for Light and Electron Optics, 126(14), 1331-1340, 2015.

[17] Mathworks. "Mathworks Documentation rgb2gray" http://www.mathworks.com/help/matlab/ref/rgb2gray. html (15.05.2016).

[18] Shapiro L, Stockman GC. Computer Vision. 1st ed. NJ, USA, Prentice Hall, 2001.

[19] Gonzalez RC, Woods RE, Eddins SL. Digital image processing using MATLAB. 2nd ed. 2009.

[20] Haralick, R.M.,Shapiro, L.G. Computer and robot vision. Addison-Wesley Longman Publishing Co., Inc.,1991.

[21] Mathworks. "Documentation Image Processing Toolbox" http://www.mathworks.com/help/images/ref/im2bw.h tml (20.05.2016).

[22] Demir Ö, Çamurcu AY. "Computer-aided detection of lung nodules using outer surface features". Bio-Medical Materials and Engineering, 26(1), 1213-1222, 2015.

[23] Lim JS. Two-dimensional signal and image processing. Englewood Cliffs, NJ, Prentice Hall, 1990. 